Title: 'Neither Confirm nor Deny: Secrecy and Disclosure in Undercover Policing'

Journal Title: Criminal Justice Ethics

\title{
Katerina Hadjimatheou
}

\begin{abstract}
Recent scandals in UK undercover policing have prompted a public re-examination of the basis for continued secrecy with respect to cases in which serious historical misconduct is suspected. As part of its approach to balancing the competing demands of secrecy and accountability, the current legal process requires the police to provide case-by-case risk assessments of the harm to policing threatened by disclosure. This paper considers the role of risk assessments in this process. It critically examines two arguments put forward by police in support of their claim that such assessments will nearly always support a refusal to disclose and thus a 'neither confirm nor deny' response to requests for information about undercover policing. It argues that these arguments apply in fewer cases and/or less conclusively than police routinely suppose, and that their obligation to provide detailed case-by-case risk assessments therefore cannot be thereby evaded.
\end{abstract}

Keywords: undercover; secrecy; disclosure; misconduct, NCND

Acknowledgements: Thanks are due to Simon McKay, Christopher Nathan and participants in the 'Democratic Secrecy' Workshop -held at the University of Manchester in September 2016- for their helpful comments on previous drafts of this paper.

\section{Neither Confirm nor Deny: Secrecy and Disclosure in Undercover Policing}

\section{Introduction}

When, if ever, should police reveal or confirm the identities of undercover officers and the tactics they use? This question has recently become the focus of heated debate in the UK, following a string of high-profile scandals and the subsequent establishment of the first-ever public inquiry into undercover policing. That inquiry is ongoing at the time of writing. It is investigating allegations (and some proven cases) that undercover police officers engaged in a range of scandalous activities. The allegations are, in brief, that a top-secret unit called the Special Demonstration Squad (SDS), formed in 1968, operated for decades monitoring British 'subversives' environmental activists, anti-racist groups and animal rights campaigners amongst others. Its unofficial motto was apparently "By Any Means Necessary". Officers stole 
the identities of dead children and used them as aliases with which to go underground for years. They engaged in sex and intimate relationships, including marriages in which they fathered children with activists, to build their credibility. They were allegedly ordered to find "dirt" on activist groups whose purpose was to uncover allegations of police corruption. And there were purported attempts to smear and discredit the families of a black teenager, whose murder the police were criticized for not bothering to investigate properly by an official inquiry. In response to a wave of such allegations, the words of a popular tabloid newspaper summed up public feeling (in characteristically sensationalist language) thus:

As our cops are shamed by cover-ups and corruption, we ask: can we ever trust them? Today, in what amounts to a national crisis of confidence, they look less like the long arm of the law and more like an organised conspiracy against the people they are meant to protect. ${ }^{1}$

The UK government's aim in setting up a public inquiry is to shed critical light on the conduct, culture, and oversight of undercover policing in the UK with a view to making recommendations for future policy and practice and, more generally, restoring public confidence and trust in what has become a seriously discredited tactic.

Yet the use of a public inquiry -which by definition operates under a presumption of openness- to investigate undercover policing -which by definition operates under a presumption of secrecy- has proven problematic. Participants and witnesses to the inquiry are bitterly divided on the issue of how much information about the activities and identities of undercover officers should be revealed and to whom. On one side, those who suspect they have been victims of police misconduct argue that the aims of the inquiry will not be achieved unless historic injustices are fully acknowledged; on the other, police insist that maintaining secrecy with respect to undercover is the only way to protect the safety of officers and their families and to ensure the continued effectiveness of a vital policing tool. Deciding where the correct balance between these competing interests lies has become a key dilemma facing the inquiry; indeed, the first year of its work has been devoted exclusively to resolving the issue of just how open and public its investigation should be.

This paper does not take sides in this debate. Neither does it defend a position on how public inquiries should resolve such dilemmas in the future. Rather, its aim is to improve the clarity and rigor of the debate by shedding critical light on a particular set of arguments put forward in this context, namely those that appeal to what will be referred to as a priori rationales for secrecy. Such arguments are interesting for a number of reasons. Though established legal opinion in this area is that decisions about disclosure should be made on the basis of a judgement about the balance of interests in any particular case, appeals to a priori arguments render empirical argument largely redundant and thus enable police to avoid conducting the risk assessment that such a balancing implies. What is more, they are taken by police to be so weighty that they are regularly called upon to defend secrecy even in the face of widespread unofficial disclosure, for example, when undercover officers write books about their experiences or otherwise publicly self-identify. ${ }^{2}$ And, they are cited often and relied upon heavily by a variety of non-police state actors seeking to justify secrecy in their activities. Thus government departments, local authorities, security agencies and counsel to all of the above regularly appeal to these a priori arguments in a wide range of contexts in which requests for disclosure are made, notably in response to the expanding use of Freedom of Information submissions. The fact that 
these arguments are used widely, relied upon heavily, and yet are (conveniently) difficult to refute by appeal to evidence makes them deserving of careful scrutiny.

Two a priori arguments are considered, starting with the most important. Each is then analyzed according to the following approach: first, there is a description of how the argument is used in practice; then an attempt is made to specify the necessary and sufficient conditions for the argument's application; and finally the contingent considerations that make the argument more or less weighty in any given case are identified. The aim of this analysis is to provide greater insight into the structure, scope and limits of these arguments and in doing so to sharpen our appreciation of what is actually at stake when different kinds of requests for disclosure are made. This, in turn, should help decision-makers in a range of state agencies reach more considered conclusions about the value of maintaining secrecy in different contexts.

The overall thrust of argument put forward in this paper is that the a priori arguments considered are less effective in sealing the case for secrecy than is often assumed by those who make them but also by those whom they seek to persuade. This overreaching occurs in one or more of the following ways; they are taken to apply in a broader range of cases than they in fact do; they are taken to carry more weight in the balance of interests than they in fact do; and/or they are taken to obviate the need for a case-specific risk assessment more often than they in fact do. If correct, these claims do not imply that there exist no compelling reasons to maintain secrecy about undercover policing as a default position. But they do suggest that that police and other agencies need to work harder to defend their decision to maintain secrecy when questions of historical police misconduct and abuse of power are at stake.

Finally, some additional features of the argument put forward here should be noted. The context and examples given are parochial to the UK, though the analysis and conclusions are relevant to any jurisdiction in which arguments of the sort rehearsed here are furthered. ${ }^{3}$ The context of the argumentation is undercover policing, but the analysis is relevant to any context in which the specific arguments are cited --and there are many. ${ }^{4}$ Finally, references to and engagement with existing work on the ethics of undercover will not feature prominently in the discussion to follow. This is because the focus of that body of work is on the justifiability of the tactics and methods used rather than on the issue of whether and to what extent to lift the cover when things go wrong. ${ }^{5}$ The arguments will instead draw heavily on the reasoning articulated by the UK government and courts in recent test cases focusing on this issue. The paper will attempt to relate this to the - currently scant philosophical literature analyzing the conflict between secrecy and accountability in a democracy.

\section{Background}

This paper began by posing the question: when, if ever, should police reveal or confirm the identities of undercover officers or the tactics they use? Put the question to any senior police officer in the UK and the response will almost inevitably be 'never'. The reasons hardly need spelling out: undercover operations only work to the extent that they remain secret; blow the cover and not only is the operation over, but the safety of police officers is at risk. What is more, useful tactics have been revealed and thereby rendered useless in the future. For these reasons, the guidance offered to UK police in the form of authorised professional practice ${ }^{6}$ is to maintain a position of 'neither confirming nor denying' any facts about undercover officers or the tactics 
they use (a stance now commonly referred to in the UK, and hereafter in this paper, as NCND).

But what if the operation is not ongoing but historical? And what if there are compelling reasons to believe (perhaps via reliable reports from investigative journalists) that the operation contravened police regulation -say by intentionally targeting peaceful protest groups? What if it involved gross misconduct sustained over a number of years, or even systematic and authorized abuses of police power? In such cases, in which things have gone wrong in ways that need to be righted, maintaining secrecy with respect to the identities and activities of officers involved comes at a cost. Part of the cost is best described as involving the interests in justice of those individuals directly affected by such actions: just as a victim of overt police brutality has a right to a process by which the wrongs done to them are acknowledged and redressed, so too do victims of abusive police deception. And part of the cost involves the interests of the public at large, interests in being reassured that coercive state powers exercised in their name are deployed in a manner that is not only effective but also legitimate and accountable.

Let us take a moment to expound this last claim about the way in which the public interest is engaged in this context, because doing so will help clarify discussion later. There is a clear public interest in having a police force equipped with considerable powers, including undercover powers, in order to prevent and prosecute rights violations in the form of crime. This interest is furthered in practice by (amongst other things) the establishment of reliable oversight mechanisms both within and external to police forces, whose role it is to ensure that powers are being used for legitimate purposes and in a proportionate manner. In order to fulfill that role, such mechanisms must be given access to confidential material that remains offlimits to the public. This is how the demands of secrecy and accountability are typically reconciled in a democracy. When such oversight fails, as it sometimes does, secrecy can become pernicious. In short, it can be used to conceal failings, misconduct, and abuses of power, and thus to undermine the legitimacy of the institution whose privilege it is.

In his 1999 article entitled 'Democratic Secrecy', Dennis Thompson analyses this conflicting dynamic between secrecy and accountability, which he calls the 'accountability/secrecy dilemma'. He argues that one of the hazards of secrecy without adequate accountability is the emergence of 'institutional hypocrisy', by which he means:

a disparity between the publicly avowed purposes of an institution and its actual performance or function that develops over time as the secrecy under which an institution or aspects of it functions enables practices that would not receive democratic consent and these become so systematic that the institution or aspects of it come to serve purposes other than those for which it was established...

Thompson's analysis is forward-looking, offering insights into how oversight mechanisms should be designed so as to maximize the benefits of secrecy without undermining accountability. It does not consider how the accountability/secrecy dilemma should be approached when such mechanisms have failed systematically in the past. Neither does it consider how it should be managed when there is a need for remedial and transitional measures to both redress specific injustices that have resulted from such failure and provide the basis for reform of oversight arrangements. 
Such considerations might be especially pertinent to cases involving the police, if we accept the British model of 'policing by consent', which makes accountability, trust and legitimacy central to the justification of policing.

Perhaps the first useful observation we can make about this challenge is that, when institutional hypocrisy is revealed and there is a clear moral imperative to acknowledge and redress it, the old conflict between secrecy and accountability reemerges with a vengeance. For, as long as the power to reveal and conceal information about undercover operations remains the privilege of the institution accused of hypocrisy, that institution faces a glaring conflict of interest: the very same privilege that enabled it to use illegitimate means and/or pursue illegitimate aims can now serve as a cloak with which to avoid criticism and calls for reform. ${ }^{7}$ At such pivotal moments, the need for greater transparency and accountability is greater than ever. This is precisely the situation that has arisen in relation to undercover policing in the UK.

As already mentioned, the government's response to this has been to appoint a public inquiry, a move which reflects a belief on the part of the UK government that more routine processes for revealing and correcting wrongs by the police, such as litigation and criminal law proceedings, would suffice neither to address the problems identified, nor to restore the damage to public confidence caused. This belief seems well-founded, for the following reasons. Focused as they are on the actions of specific individuals, legal processes are not particularly effective at revealing and redressing cases of institutional hypocrisy, 'bad organizational culture', and systemic problems such as ineffective oversight or excessively permissive spheres of discretion. ${ }^{8}$ In addition, while such proceedings may deal with known or suspected cases of individual abuses, they would not reveal cases that are currently unknown. Not only would this deny as-yet-unidentified victims the chance to seek justice, it would also conceal from the public the full extent of the illegitimacy that has occurred, risking an inadequate appreciation of the extent of reform needed. Finally, a more prosaic consideration: UK judges have not demonstrated a willingness to second-guess the statements of police with respect to the security implications of disclosures in the past. $^{9}$

Despite the fact that a public inquiry operates by definition on a presumption of openness, ${ }^{10}$ police submissions to initial hearings of the UK inquiry asserted an intention to maintain a position of NCND with respect to the identities of officers and tactics used in almost all envisaged cases. ${ }^{11}$ This is problematic, not because a public inquiry removes the police's right to refuse to disclose (it does not), but because established legal opinion is that the decision to neither confirm nor deny some fact must be made on a case-by-case basis, not as a general or blanket policy. In the words of Lord Pitchford, the chair of the undercover inquiry:

In each case an assessment of the public interest is made. Disclosure is made only when in the particular circumstances of the case the level of the risk of harm that may follow the particular disclosure sought is sufficiently low that the public interest in disclosure can prevail. ${ }^{12}$

In other words, the balance between accountability and secrecy is achieved by means of a rule stating that when disclosure is sought for reasons that are prima facie legitimate, including reasons of alleged misconduct or other police injustice, the police must defend continued secrecy by means of a risk assessment and present the 
results of this, though not the confidential detail, to the court (or in this case, the chair of the inquiry).

The moral purpose served by the requirement to provide a risk assessment is that of ensuring that secrecy is not used to conceal wrongdoing or deflect investigation but to protect a public interest. The provision of a risk assessment demonstrating a threat to the public interest does not resolve the dilemma between secrecy and accountability; on the contrary, it is evidence both of the existence of a genuine dilemma and of the challenge it poses. In the context of normal freedom of information requests, the police both conduct the risk assessment and determine the correct balance between the competing public interests. But in the context of court cases or public inquiries the balancing exercise is carried out by the independent arbiter, in this case the chair of the Inquiry.

The need for a case-by-case risk assessment is regularly acknowledged in UK police submissions to the public inquiry, a fact that seems inconsistent with their even more frequent assertion that NCND must be maintained in all but rare and exceptional cases. Thus, for example, the National Police Chief's Council recognizes the need for a case-by-case risk assessment, citing their awareness of the unambiguous assertion of the UK appeal court ${ }^{13}$ that neither confirming nor denying

is not a 'doctrine' to be hoisted up and saluted on every occasion. Rather, it will always be for the party claiming reliance on NCND to clearly articulate the potential damage which would arise were there to be a departure from NCND and it should be considered on a case by case basis. ${ }^{14}$

The reason this seems inconsistent with the police's actual insistence on secrecy as a modus operandi for the inquiry is that it is not unreasonable to suppose that the 'potential damage' is likely to vary considerably between cases. For example, it seems plausible that the potential damage is likely to be much greater when the information relates to the identity of an undercover officer than to the use of a specific tactic, ${ }^{15}$ or when it relates to facts about an operation that ended very recently, rather than one that ended decades ago. In order for the police's recognition of the need to undertake a case-by-case risk assessment to be rendered consistent with their claim that (almost) all future requests for disclosure will be met with an NCND response, they must be convinced that those future cases will both inevitably and invariably fail the risk assessment. It is to a critical appraisal of the basis for such a conviction that the focus of this paper now turns.

What kinds of reasons do police have for believing that it will (almost) never be in the public interest for them to either confirm or deny facts about undercover operations? Two distinct but compatible reasons are typically given. The first is the argument that requests for disclosure must be met consistently with a refusal to confirm or deny, otherwise dangerous precedents will be created. The second claims that to disclose even limited and discreet details of undercover policing risks revealing far more than is desired by providing criminals inadvertently with the last piece in the information 'puzzle'.

In the introduction to this paper these arguments were referred to as a priori. Though the term does not feature in public debate in relation to such arguments, it is useful for our present purposes, because it invites contrast with arguments whose soundness is contingent upon consultation of empirical considerations. There are two ways in which the arguments considered can be described as a-priori. First, they are taken to apply to all or nearly all cases in which requests for disclosure are made, 
irrespective of the distinctive features of such cases; second, they are taken to carry both priority and decisive weight in the balance of interests, thus (somewhat paradoxically) rendering such a balance redundant. In sum, insofar as they do in fact demonstrate the need for secrecy in any given case, these arguments do so in the abstract, without reference to any specific facts about that particular case. It is this a priori feature that lends these arguments to use as reasons for maintaining NCND as a policy or blanket response to requests for information about undercover policing, thereby obviating (or evading, depending on how one sees it) the need for a case-bycase risk assessment.

The weight and scope of application of each of these arguments is different, as will become clear in the analysis to follow. However, for the purposes of this paper it is assumed that if either of these arguments is convincing, then the case for a blanket policy of NCND is strong and police are justified in maintaining it. It is then argued that in fact neither of them justifies such a policy. Therefore, it is concluded, police continue to be obliged by considerations of the just balance between secrecy and accountability, to undertake risk assessments for each case in which disclosure is requested. This conclusion does not exclude the possibility that in practice all risk assessments end up favoring an NCND response to the request. But that is beside the point; the point is that the potential damage of not giving such a response must be demonstrated in each case rather than assumed in advance. Let us now turn to a consideration of each of those arguments.

\section{A priori arguments for secrecy}

\section{The argument from danger and consistency: the case of Scappaticci}

In May 2003 reports were published in the British media that the security services' most valuable informer in the IRA, an agent known as Stakeknife, could be named as the Belfast man Freddie Scappaticci. Scappaticci quickly moved to deny the allegation and began legal proceedings to force the UK government to do the same, citing threats to his life, including the placing of a pipe bomb in his house, in support of his case for disclosure. The UK government responded by neither confirming or denying the alleged facts. The argument put forward by the government in support of its position is cited often in the context of debates about disclosure of information about undercover operations, in order to show that consistency is necessary even in cases in which there appears to be a legitimate interest in disclosure. It has featured prominently in the current debate in the UK over disclosure of what is alleged to be systematic historical misconduct and abuse of police powers, as police appeal to it in their demands that the public inquiry conceal the identities and tactics of undercover officers allegedly involved. It is replicated here in full:

The Government has a long established policy in respect of the identification of agents. The policy involves the principle that the identity of agents is neither confirmed nor denied (hence it is sometimes referred to as the NCND policy) as-

- to confirm that a person is an agent would place that person in immediate and obvious danger;

- to deny that a person is an agent may place another person in immediate and obvious danger; and 
- to comment either way in one case raises a clear inference the Government refuses to comment in another case that it has something to hide in that case, ie the inference will be that the individual in that case is an agent, and he may be subject to reprisals (and his life may be at risk) as a result. ${ }^{16}$

The argument is a general one about the effect of state disclosure of information about the identity of any informer on the aggregate or overall risks to informers. Its soundness becomes especially clear when we consider the nature of the interests at stake and the extent to which legitimate interests would in fact be protected by disclosure. For there is no legitimate interest of the public in knowing who is or who is not an informer for the security services. Indeed, the only people who want such information do so in order to further illegitimate purposes, namely the infliction of serious harm, maybe even murder, on anyone directly or indirectly thus identified. Agents have a legitimate interest in being protected from such harm, but they have no right that that interest be served by means of the provision of official information about their status as informers or otherwise. In other words, their interest lies in the cessation of threats, not in disclosure as such. This interest can be protected by the state in the same way it protects any other individual subject to harassment and threats to life, namely via police protection and police investigation and prosecution of those carrying out such crimes. The absence of any legitimate interests in disclosure means there is no prima facie obligation on the part of the authorities to make a public disclosure. On the contrary, the argument set out above provides a prima facie case for maintaining NCND.

Scappaticci's lawyer responded to the submission of this argument by emphasizing the seriousness of the threat to his client's life and claiming that this distinguished his case from others, a fact which, he argued, had not been taken into account adequately by the government. In short, his complaint was that the government was applying the policy in a blanket way, without conducting the requisite risk assessment. An application for judicial review of the NCND decision was lodged with the courts. The court rejected it, pointing out that the government had made statements about the specifics of the case, and that these served only to strengthen the prima facie case already made. Those statements were to the effect that the paramilitary terrorists currently threatening to kill Scappaticci had their own methods of ascertaining the identity of informers and that the statement of a minister would in any case be unlikely by itself to allay any suspicions they had. ${ }^{17}$ Even if it were true that by providing a statement the threat to Scappaticci would be alleviated, such a move would only displace the threat elsewhere, as it provided reasons for the IRA in its search for Stakeknife to begin to cast suspicion on others.

Emphasizing the seriousness of the threat, as Scappaticci's lawyer did, does not undermine this last of the government's points. On the contrary, the more serious the threat to the agent in question, the more serious the threat displaced to others as a result of disclosure; raising the stakes on one side of the argument merely raises them on the other. There are conceivable exceptions to this. For example, if the agent in question (in this case Stakeknife) had died, then full disclosure of his identity would protect Scappaticci without displacing the threat to him to anyone else. Yet, such a move would create a precedent that would support dangerous inferences in the future because a refusal to confirm or deny would now imply the continued existence of an agent. For this and all of the reasons provided above, the argumentation provided by the government in support of NCND in respect of Scappaticci seems 
straightforwardly valid and conclusive.

The question we must now address is whether and to what extent that reasoning holds for undercover operations. Recall that police in the UK appeal to the reasoning provided by the government in Scappaticci to defend their stance of NCND as providing not only a prima facie but also an a priori case in favour of NCND. In other words, they take the reasoning in Scappaticci to apply so convincingly to the realm of undercover policing as to obviate the need for a case-by-case risk assessment. In order to assess whether this position is justified, we must first identify the conditions that should pertain in order for the Scappaticci reasoning to hold and then consider the extent to which they apply in cases of undercover policing.

The following claim is now defended: the weight of the case against disclosure made by Scappaticci reasoning is a function of the seriousness of the harm threatened. If the risk of harm is very slight, the reasoning still applies, but does not make as strong a case against disclosure as it would if the risk of harm were very great. If there is no risk of harm then the reasons given in the Scappaticci case for refusing to disclose (and only those reasons) disappear. They disappear not only in relation to the specific case, but also in relation to the creation of a precedent. This is because, in the absence of a threat of harm, the precedent created by disclosure would only justify the inference that 'police might disclose when there is no risk of harm'. Such inferences would not be weapons in the hands of those who wish to do harm to those identified as agents, because the very fact that there are individuals who would wish to do harm to those identified would disqualify the case from being captured by the precedent.

From this we can draw support for the continued assertion of a prima facie presumption against disclosure both in the case of informers working-like Stakeknife- for the security services and for undercover police. In the case of the security services, the risk of harm is, in nearly all conceivable cases likely to be very high, because the use of agents is restricted to matters of national security, which by their very nature involve serious threats to life and serious criminality such as, for example, terrorism. A similar case can be made for undercover police officers, because their use is in principle authorised only in the context of investigations of serious offences. However, with respect to undercover policing, it is less easy to draw support from this for the assertion of an a priori case against disclosure. For experience shows that there is a range of different cases in which the risk of harm from disclosure is negligible. At least three such cases are discernable, each of which are now considered in turn.

The first case occurs when the agent's identity as an undercover officer has already been confirmed by the agent themselves, an event known as selfidentification. In DIL, a recent UK legal case brought by 5 women who suspect they were illegitimately duped into relationships with officers working undercover, the presiding judge, Justice Bean, rejected the police's claim that it could maintain NCND in cases in which undercover officers had self-identified. In doing so, Bean reasoned that the act of self-identification itself exposes the agent to any danger such disclosure threatens to bring upon him. The harm has therefore already been done. Thus the justification for refusing the police the privilege of continued secrecy in cases of self-identification follows 'not from a waiver of privilege attaching personally to the informer, but from the disappearance of the primary justification for the claim for secrecy, which is the protection of informers and the technique."18

Now, it has been argued in submissions by the police to the inquiry that allowing self-disclosure to create an exception to NCND could over time lead to pressure on informers or undercover officer to out themselves. ${ }^{19}$ But this seems 
unlikely. For one thing, such pressure would only be imposed by someone who knows already that the individual is an agent and wants to do them harm. If that is the case, then it makes more sense for the informer to seek protection from the police from those making the threats than to capitulate and self-identify, because the alternative is to risk being threatened by those who might react badly to being alerted to their role as an informer. In either case, the informant is subject to threats of harm from which they have a right to be protected by the state.

The second case in which disclosure threatens no or negligible harm thus negating the Scappaticci reasoning occurs when an agent's identity has already been authoritatively confirmed by some relevant entity. Thus in relation to an officer whose undercover identity had been revealed by the Commissioner of the Metropolitan Police Service, it was argued (again by Justice Bean, in the DIL case) that further "reliance on the NCND policy to avoid admitting that he was an UCO is simply unsustainable.$^{20}$ In reaching this conclusion, Justice Bean made no attempt to assess the existence or otherwise of a risk of harm to undercover officers or to the long-term effectiveness of the tactic. His argument was not substantive but formal- authoritative disclosure has already occurred; it follows that, whatever harm would be avoided by secrecy has already been done. Disclosing adds no additional risk of harm to that already posed. Therefore the primary reasoning provided by police in support of their refusal to disclose, namely the reasoning of the government in the Scappaticci case, simply did not apply.

While Justice Bean recognized that there could in principle be cases in which police disclosure would bring a risk of harm additional to that already done by selfidentification or other authoritative disclosure, he noted that police had provided no evidence to suggest that it would in the specific case in question. In other words, in the absence of a risk assessment by police suggesting additional harm, there was no reason to assume such harm would occur. Thus his reasoning can be summed up as supporting the claim that, while Scappaticci provides a prima facie case in favour of secrecy in undercover policing, self-identification or authoritative disclosure overturns that case.

The third case in which disclosure would not pose enough of a threat to harm for the Scappaticci argument for secrecy to apply is less straightforward and does involve the kind of substantive reasoning about the risks on both sides that Justice Bean refrained from when proposing the two exceptions just mentioned. Specifically, it involves reference to the existence of a threat of harm to agents by nefarious individuals. Assessing this threat involves in the first instance establishing the motivations either of those seeking disclosure or of those driving the request for it. In Scappaticci, those driving the request for disclosure were doing so for clearly nefarious reasons: they were terrorists whose aim was to find and kill Stakeknife, as they demonstrated by putting a pipe bomb in Freddie Scappaticci's house. In contrast in the case of DIL, those requesting disclosure were not terrorists but members of peaceful protest groups; their motivations were not nefarious but rather involved a legitimate quest for justice. There is no reason to believe that they would be more likely to use the information disclosed to inflict harm on officers than there is reason to believe that victims of crime would pose a threat to those who are taken to court for the perpetration of those crimes. Neither is there reason to believe that there are others out there who would use this information to inflict harm on officers. This supposition is borne out by the fact that recent revelations in the British media about the identities of some of those officers have not been met with threats to life or other serious threats of harm. 
It is worth noting at this point that the options available to public inquiries (and indeed to police) dealing with requests for disclosure are more varied than a simple choice between disclosure that is fully public or no disclosure at all. Disclosures can in principle (and have in practice) been made to specific individuals who are deemed to have a legitimate interest in knowing and to pose no threat, on the condition that those individuals remain legally bound to refrain from sharing the information. Or, in the context of an investigation into police wrongdoing, 'circles of confidentiality' can be created, to enable the engagement of witnesses and other relevant individuals without disclosing beyond what is required by the demands of justice. Risk assessments carried out by police should pertain to all relevant options.

The points made thus far serve only to show that the reasoning that was put forward in Scappaticci -and is now cited as conclusive by police seeking to justify secrecy with respect to undercover- does not obviate the need for police to undertake case-by-case risk assessments when faced with requests for disclosure. That need is not obviated because, while it is a necessary condition of the application of that reasoning that a serious threat of harm exists, that condition is not met in at least three kinds of cases involving requests for disclosure: cases in which undercover officers have been identified by the police or equivalent authoritative source; cases in which they have self-identified as agents; and cases in which disclosure would not enable the carrying out of implicit or explicit threats to the safety of officers. For this reason, police cannot appeal to Scappaticci as a model response for all requests for disclosure; Scappaticci reasoning may well apply to the case in question, but whether it does or not is a matter for the police to demonstrate, not for the courts or the chair of a public inquiry to disprove.

Finally, none of this should be taken to imply that if Scappatici fails to apply then the case for non-disclosure has also failed. The case for or against disclosure is made only on the basis of a balance of interests, and this involves considerations beyond a mere demonstration that disclosure will not result in serious harm to an agent.

\section{The argument from the mosaic effect}

The second argument put forward by police as an a priori reason to assert secrecy in undercover policing is known as the 'mosaic effect' for reasons that will soon become clear. Before examining it in detail, some preliminary observations about the distinction between the mosaic effect and Scappaticci are in order. Whereas the reasoning from Scappaticci applies only in cases in which there is a real danger to agents, the mosaic effect applies even when no such danger is apparent. Whereas Scappaticci is used to defend secrecy around the identity of agents in particular, the mosaic effect is used to defend secrecy about any feature or aspect of undercover operations. The mosaic effect is taken to show not that disclosure always threatens serious harm to agents, but rather that it is impossible to assess that harm with sufficient certainty to justify ever taking the risk. Its distinctive feature is this apparent ability to justify blanket secrecy as a precautionary response to the inadequacy of case-by-case risk assessments.

The mosaic effect occurs when a piece of information disclosed after an apparently reassuring risk assessment is combined with other pieces of information already in the possession of those with bad intentions, to reveal identities or tactics and thus to cause harm to officers and/or to scupper operations. Technological developments are often taken to make the risk of indirect and unintentional but 
nevertheless harmful disclosures higher, given the possibilities afforded to criminals for cross-referencing open-source and other forms of information. Disclosure of specific tactics could in principle be combined with information about individuals to reveal their identities, while disclosure of identities could expose and thereby render redundant valuable tactics. Because we can never know for sure what kind of information the bad guys already have, we can never know whether the piece we are about to disclose completes the mosaic. The National Police Chiefs Council articulates the argument thus:

The determination and quest for information from individuals and organisations, extensive research capabilities afforded by the internet and modern communication technologies, creates a mosaic effect that is capable of identifying, the covert methods and techniques used by law enforcement, endangering individual undercover operatives, their families and colleagues and may ultimately even result in the loss of life. ${ }^{21}$

This reasoning embodies a precautionary approach to risk-assessment in the area of undercover policing, i.e. the absence of certainty about the risks to agents from disclosure is itself taken to justify continued secrecy.

The mosaic effect highlights a genuine limit to the ability of risk assessments to provide the kind of reassurances that are reliable enough to support disclosure with confidence. But its success in providing a case for jettisoning those risk assessments in favour of an a priori case for secrecy is limited, for at least three reasons. First, uncertainty about risks is not by itself sufficient reason for taking none, especially when the costs of continued secrecy are high. Secondly, in some cases, namely at least those named in the discussion of Scappaticci above, the risks of disclosure (both current and future) are negligible. Thirdly, a precautionary approach cites the fact that we don't know something as a reason to ignore or discount what we do know. As a result, it obscures the fact that the risk of harm threatened by disclosure is likely to be smaller in some cases than others and that this likelihood should inform and be reflected in final decisions about disclosure.

This latter point merits more detailed explanation. The risk of disclosure is likely to be higher in some cases than others because it is a function of the following three considerations: a) the existence of people or groups with nefarious intentions in relation to undercover officers; b) the sophistication of the fact-finding capabilities of those with nefarious intentions; and c) the likelihood that the piece of information whose disclosure is requested could be combined with existing information and thereby rendered identifying. It is not necessary here to make an attempt to determine the risk threshold at which each of these considerations (or indeed at which the combination of all three) begin to weigh in favor of continued secrecy. The point being made is simply that the case for individual risk assessments is not overturned by the possibility of a mosaic effect. On the contrary, the uncertainty posed by the recognition of the risk of a mosaic effect should be incorporated into the risk assessment.

\section{Outstanding issues}

Thus far it has been argued that neither of the two arguments against disclosure most commonly voiced by police do not, contrary to what is often supposed, provide an exemption from the duty to conduct a case-by-case assessment of the risks of such disclosure. In addition, some suggestions regarding the content of risk assessments 
have been put forward. Case-by-case risk assessments provide objective reasons for secrecy in the face of legitimate requests for disclosure (or at least evidence of their existence). The requirement to provide them is intended to prevent police using the same privilege that was used as a cloak for misconduct and abuse to evade or deflect accountability for those wrongs, thus going some small way to resolving accountability/secrecy dilemma.

But just how small a contribution are such risk assessments likely to make? At least two features of the process they form a part of lead to the suspicion that the focus on them in this paper (and indeed in the work of the Inquiry) is no more than an exercise in splitting hairs and what is more an unwelcome distraction from the fundamental moral question at hand, namely how to do justice to victims of undercover police misconduct given the need for secrecy. The first of these features is the fact that such assessments are the privilege of the police, who have serious vested interests in shaping them in such as way as to support secrecy. The second is that judges are in fact disinclined to question the police about the basis for such assessments, considering correctly that their lack of access to the evidence means they lack the authority to do so. As Rahul Sagar explains in his paper on combatting the abuse of state secrecy, both of these features arise from the structure of transparency and accountability mechanisms:

... given that we wish to scrutinize the executive because we fear the abuse of state secrecy, asking officials to calculate the harm caused by disclosure is like asking the suspect to provide the evidence. In other words, the fundamental flaw in proposals to increase transparency is structural in nature because their success is destined to rely upon the faithfulness of officials, which is ironic since the point of the whole exercise is to prove rather than assume their good faith. $^{22}$

The risk is that the assessments are an empty formality, by which police merely reassert their immunity from meaningful accountability for past wrongs while maintaining a veneer of transparency. In which case, of course, they seem hardly worth defending.

One approach to dealing with this conflict of interest would be to appoint an independent body to oversee the risk assessments. The problem of judicial deference and of partisanship could be addressed by appointing a single independent ombudsman, perhaps along the lines of existing mechanisms such as the UK's highly effective Independent Reviewer of Terrorism Legislation. ${ }^{23}$ Alternatively, the issue could be brought to existing parliamentary committees for consideration, as these are less likely to suffer from the distortions of political partisanship when scrutinizing a non-executive arm of government such as the police. Both such approaches could produce opinions that might form the basis for guidance for how future cases should be dealt with. The general gist and some redacted sections of such guidance could be made public for scrutiny, thus both providing the basis for enhanced accountability and making approaches to disclosure more consistent. Unless and until such options are seriously explored, the main challenge to the police's production of self-serving risk assessments will continue to be provided by the steady stream of leaks, confessional publications, and investigative journalism that currently characterizes this area of police activity.

\section{Conclusion}


Secrecy is a necessary prerequisite of certain valuable state functions, among which we can count with confidence undercover policing. In a democracy, the secrecy afforded to the police must be rendered accountable. This is usually achieved via effective oversight mechanisms, which have access to material rightly concealed from the public. When such mechanisms fail, as they have done quite spectacularly in the UK, a recalibration of the balance between secrecy and accountability is required. In the short run, this may involve greater-than-usual, indeed exceptional openness. This may be necessary not only to attain justice for those mistreated, but also to reestablish trust and, perhaps most importantly, in order to reveal where and why things went wrong so that the same mistakes will not be repeated in the future.

Recent attempts by UK police to employ a priori reasoning in support of secrecy in order to resist the requirement to perform risk assessments have been contested here. Accountability in a democracy does not require disclosure of all information held by the state, nor even of the specific reasons why such information should be protected or concealed. But it does require some objective reassurance that such reasons in fact exist, which is precisely what risk-assessments are designed to provide. The public is owed that much by those who act in their name.

\section{Bibliography}

College of Policing and National Undercover Working Group Revised (Draft) Authorized Professional Practice on Covert Policing. Accessed $1^{\text {st }}$ September 2016. http://www.app.college.police.uk/app-content/covert-policing/undercover-policing/

\section{DIL and others $v$ Commissioner of Police of the Metropolis}

Dworkin, Gerald 'The Serpent Beguiled Me and I Did Eat: Entrapment and the Creation of Crime' in Law and Philosophy 4(1), 1985. 17-39

Green, David Allen. 'Hidden Agreements on Justice and Policing: UK's Appeasement of Saudi Arabia', The Financial Times, 12 October, 2015. Last Accessed 29 December 2016 at: http://blogs.ft.com/david-allengreen/2015/10/12/hidden-agreements-on-justice-and-policing-uks-appeasement-ofsaudi-arabia/

Howard, Jeffrey. 'Moral Subversion and Structural Entrapment'. Journal of Political Philosophy, 2016. 24-46.

Information Commissioner's Office (UK). When to Refuse to Confirm or Deny Information is Held. 2013. Last Accessed 29 December 2016 at https://ico.org.uk/media/1166/when_to_refuse_to_confirm_or_deny_section_1_foia.p df

Joh, Elizabeth. 'Bait, Mask, and Ruse: Technology and Police Deception', Harvard Law Review Forum. 2015. 245-252. 
Kavanagh, T. The Sun Newspaper, 26th June 2013. Last Accessed 5 September 2016. https://www.thesun.co.uk/archives/news/823249/as-our-cops-are-shamed-by-coverups-and-corruption-we-ask-can-we-ever-trust-them/

Kleinig, J. Handled with Discretion: Ethical Issues in Police Decision Making. Rowman and Littlefield, 2016.

Lewis, Paul, and Rob Evans. Undercover: The True Story of Britain's Secret Police. London: Guardian Faber Publishing, 2014.

Loftus, B., Goold, B., and Giollabhui, S. 'From a Visible Spectacle to an Invisible Presence: The Working Culture of Covert Policing', British Journal of Criminology, 56(4), 2016.

Marx, Gary T. 'Ethics of Undercover Investigations'. In Encyclopedia of Applied Ethics, edited by Callahan, Dan, Singer, Peter, and Chadwick, Ruth. Academic Press, 2011.

Marx, Gary T. 'Under-the-covers Undercover Investigations: Some Reflections on the State's Use of Sex and Deception in Law Enforcement'. Criminal Justice Ethics 11, no. 1 (1 January 1992): 13-24.

McKay, Simon. Covert Policing: Law and Practice. 2nd edition. Oxford: OUP, 2015.

Mohamed and CF vs Secretary of State for the Home Office, Court of Appeal Judgement, 2014. https://www.judiciary.gov.uk/wp-

content/uploads/2014/05/mohamed-and-cf-v-sshd.pdf

National Police Chiefs Council, 'The Undercover Policing Inquiry: Submissions on Behalf of the NPCC (National Police Chiefs Council) on the Principle of Neither Confirm Nor Deny' March 2016. Accessed 1s September 2016.

https://www.ucpi.org.uk/wp-content/uploads/2016/03/160121-submissions-on-theNCND-principle-NPCC.pdf

Norris and Kristensen, 'Global Nuclear Weapons Inventories, 1945-2010'. Bulletin of the Atomic Scientists, 66(4), 2010.

Sagar, Rahul. "On Combating the Abuse of State Secrecy". Journal of Political Philosophy, 15(4), 2007. 404-427.

Savage vs Chief Constable of Hampshire, 1997. 1 WLR, 1061.

Northern Ireland High Court, Queen's Bench Division. Judgement in the Matter of an Application by Freddie Scappaticci for Judicial Review. Delivered 18/8/2003.

Accessed $6^{\text {th }}$ September 2016. https://www.courtsni.gov.uk/enGB/Judicial\%20Decisions/PublishedByYear/Documents/2003/2003\%20NIQB\%2056 /j_j_CARC3995.htm

Skolnick, Jerome H. 'Deception by Police'. Criminal Justice Ethics 1(2). 1982. 40 54. 
Undercover Policing Inquiry, 'Preliminary Hearings on the Legal Principles that Apply to Applications for Restriction Orders Under Section 19 of the Inquiries Act 2005'. Transcript, 22 March 2016. Accessed 15 September 2016, https://www.ucpi.org.uk/preliminary-issues/restriction-orders-legal-approach/.

Undercover Policing Inquiry, 'Restriction Orders: Legal Principles and Approach Ruling', $3^{\text {rd }}$ May, 2016. Accessed 15 September 2016. https://www.ucpi.org.uk/wp-content/uploads/2016/05/160503-ruling-legal-approachto-restriction-orders.pdf

Walker, Clive, and Kingsley Hyland. 'Undercover Policing and Underwhelming Laws'. Criminal Law Review, no. 8. 21 March 2014.

Wessler, Nathan F. "We Can Neither Confirm Nor Deny the Existence of Records Responsive to your Request: Reforming the Glomar Response under FOIA", $N Y U$ Law Review, 85, 2010. 1381-1416.

${ }^{1}$ Kavanagh, T. 'As our cops', 2013.

${ }^{2}$ Lewis, Paul and Evans, Rob, Undercover, 2014.

${ }^{3}$ Due to the scarcity of research published in this specific area outside of the USA, it is difficult to know how relevant it is likely to be in practice. While there is some evidence that governments around the world will neither confirm nor deny details of and sometimes even the existence of nuclear weapons programs (see, for example, Norris and Kristensen, 'Global Nuclear Weapons', 2010) there are few accounts of how it is used in other contexts, including the criminal justice context.

${ }^{4}$ The arguments are cited in the context of responses to freedom of information requests, mainly in Anglo-American jurisdictions, but relevant to any area of government conduct. For example, the term NCND has been enshrined in US law in Part II of the Freedom of Information Act (FOIA) 2000. And, in the UK, the Information Commissioner's Office has recently produced guidance for public bodies on when to refuse to confirm or deny the content of information or their possession of it (ICO, 'When to Refuse to Confirm or Deny', 2013.). The NCND response has recently been cited in a non-operational matter by the UK's professional policing body, the College of Policing, in response to a query about the nature of and remuneration for work they provided to Saudi Arabian law enforcement bodies. For a discussion of the problematic nature of the latter resort to NCND, see Green, 'Hidden Agreements', 2015.

${ }^{5}$ There is, for example, a significant stream of work looking at the ethical risks of using different kinds of deception, see Skolnick, 'Deception by Police', 1982; Joh, 'Bait, Mask and Ruse', 2015; Marx, 'Under-the-covers', 1992. A distinct area of philosophical and legal analysis examines the normative aspects of entrapment. See, for example: Howard, 'Moral Subversion', 2016; Dworkin, 'Entrapment', 1985.

${ }^{6}$ College of Policing and National Undercover Working Group Revised (Draft) APP, 2016.

${ }^{7}$ Wessler 'We Can Neither Confirm' 2010: 1384 makes a similar point in his paper on the use of the NCND response in relation to freedom of information requests in the USA. 
${ }^{8}$ As a recent ethnographic study of undercover policing in the UK reveals, the challenges of supervising and rendering accountable a 'diffused set of employees who exercise considerable discretion' is 'compounded in the undercover context' (Loftus, Goold and Giollabhui, 'The Working Culture of Covert Policing', 2016, p.630). In such contexts, police inevitably exercise considerable discretion to selectively enforce the law, a fact whose legitimacy has been questioned, see the discussion between Jeffrey Reiman and John Kleinig in Kleinig, J. Handled with Discretion, 1996. ${ }^{9}$ For ample evidence of this, see Walker, Clive, and Hyland, Kingsley. 'Undercover Policing', 2014.

${ }^{10}$ Undercover Policing Inquiry, 'Restriction Orders', $3{ }^{\text {rd }}$ May 2016.

${ }^{11}$ Hall on behalf of Metropolitan Police Service, in Undercover Policing Inquiry 'Preliminary Hearing' p.2.

${ }^{12}$ Undercover Policing Inquiry, 'Restriction Orders', $3^{\text {rd }}$ May 2016, paragraph 127.

${ }^{13}$ Mohamed and CF vs Secretary of State for the Home Office, Appeal, 2014.

${ }^{14}$ National Police Chiefs Council, Submission, 2016.

${ }^{15}$ By tactic is meant here any operational method or act used. A tactic could be an adhoc activity specific to a particular case, or a standard procedure used in all cases.

Generally speaking, disclosure of the latter is likely to carry higher risks. This is because exposing widely-used tactics can render them unusable in the future and can also risk exposing the identities of officers who used them. The adoption by undercover officers in the UK of dead children's identities is one such example.

${ }^{16}$ Sir Joseph Pilling KCB, the Permanent Under-Secretary of State of the Northern Ireland Office in High Court of Northern Ireland, Scappaticci, 2003, [6]3

${ }^{17}$ Lord Justice Carswell, Scappaticci, 2003.

${ }^{18}$ Lord Justice Judge, Savage vs Chief Constable of Hampshire, 1997. 1067D

${ }^{19}$ Hall on behalf of Metropolitan Police Service, in Undercover Policing Inquiry 'Preliminary Hearing' p.58.

${ }^{20}$ Lord Justice Bean, DIL, 2014, para. 45.

${ }^{21}$ NPCC, Submission, 2016, p.18-19.

${ }^{22}$ Sagar, Rahul, 'On Combatting the Abuse', 2007, p.408.

${ }^{23}$ See https://terrorismlegislationreviewer.independent.gov.uk 